\title{
The Unbearable Whiteness of Being: The Racial Production of Architecture and Architects
}

\author{
B.D. WORTHAM-GALVIN \\ Clemson University
}

\author{
JACKIE MCFARLAND \\ Portland State University
}

In order to address the ethical challenges that President Donald Trump's administration continues to generate, race needs to be explicated addressed not only in the demographics of architecture schools and firms, but also in acknowledging that architecture in the United States is taught and practiced with racial bias. The problem-identified and made explicit by civil rights activist Whitney Young 50 years ago-cannot be solved through a head count alone because it is also a problem of the presumed neutrality of whiteness and the invisibility of blackness in both the episteme of the American identity and as it blankets the teaching and praxis of architecture in the United States. Architecture, thus, is political; in spite of the fact that architectural education and practice has been naturalized throughout the 20th and into the 21st century to focus on just the objects-as if the contexts were only physical and not political. Trump is a manifestation of a deeper problem in the United States wherein we render our socio-political contexts neutral. Young pointed this out fifty years ago and yet our response has been anemic. In order to address the continued "complete irrelevance" of architectural education and practice, this paper will: 1). Conceptualize notions of whiteness and blackness and how they operate in the United States; 2). Delineate the architectural implications of whiteness and blackness; and, 3). Begin a discussion of how architectural schools can explicitly address this issue.

\section{INTRODUCTION}

"[...] you are not a profession that has distinguished itself by your social and civic contributions to the cause of civil rights, and I am sure this has not come to you as any shock. You are most distinguished by your thunderous silence and your complete irrelevance. [...] As a profession, you ought to be taking stands on these kinds of things. [...] if you don't speak out [...] then you will have done a disservice [...] most of all, to yourselves." -Whitney Young ${ }^{1}$

"We urge both the incoming Trump Administration and the new Congress to work toward enhancing the design and construction sector's role as a major catalyst for job creation throughout the American economy. [...] It is now time for all of us to work together to advance policies that help our country move forward." -Robert Ivy, on behalf of the American Institute of Architects $^{2}$
As we approach the fiftieth anniversary of civil rights leader Whitney Young's now famed quote, it appears that little has changed in spite of his exhortation. ${ }^{3}$ Instead of taking up Young's call to arms, the thunderous silence has continued as architecture wears the mask of assumed neutrality and supposed a-politicism. The open letter produced by the American Institute of Architects following President Donald Trump's election speaks to architecture's continued denial of its socio-political role. While Ivy's statement was quickly denounced based on the politics of Trump, few made clear that architecture is a political proposition and, therefore, needs to articulate a clear position through both architectural processes as well as products. In speaking for those at odds with the AIA statement, architectural critic Michael Sorkin pressed,

We do not welcome Donald Trump to the White House and will revile and oppose him until he can conclusively demonstrate that the hideous pronouncements and proposals of his campaign have demonstrably been set aside and in favor of positions and actions that genuinely seek to serve our national cause and purpose to build a better America rooted in the principles of justice, equity, and human dignity. ${ }^{4}$

Sorkin's denunciation of Ivy's statement needs to be translated into an actionable ethics and politics of architecture, instead of being deflected back to the ethics and policies of the Trump Administration itself. In order to address the ethical challenges that Trump's organization and his administration continue to generate, race needs to be explicitly addressed not only as it concerns the demographics of architecture schools and firms, but also in acknowledging that architecture in the United States is taught and practiced with racial bias.

The demographics of the problem are clear with NCARB reporting 105,847 registered architects (2015) with the Directory of African American Architects containing only 2,136 self-reporting licensed members (2017). ${ }^{5}$ No one can quibble that these anemic numbers are a problem. In fact, most schools show awareness that they have a demographic problem among their faculty and students and some even are actively working to change that. Nevertheless, the problemidentified and made explicit by Young-cannot be solved through a head count alone because it is also a problem of the presumed neutrality of whiteness and the invisibility of 
blackness in both the episteme of the American identity and as it blankets the teaching and praxis of architecture in the United States. Architecture, thus, is political; in spite of the fact that architectural education and practice has been naturalized throughout the 20th and into the 21st century to focus on just the objects-as if the contexts were only physical and not political. Trump is a manifestation of a deeper problem in the United States wherein we render our socio-political contexts neutral. Young pointed this out fifty years ago and yet our response has been anemic. In order to address the continued "complete irrelevance" of architectural education and practice, this paper will: 1). Conceptualize notions of whiteness and blackness and how they operate in the United States; 2). Delineate the architectural implications of whiteness and blackness; and, 3). Begin a discussion of how architectural schools can explicitly address this issue.

\section{THE SOCIAL PRODUCTION OF BLACK BODIES IN AMERICA}

"We are a racist nation, and no way in the world could it be otherwise given the history of our country. Being a racist doesn't mean one wants to go out and join a lynch mob or send somebody off to Africa or engage in crude, vulgar expressions of prejudice. Racism is a basic assumption of superiority [...]"-Whitney Young ${ }^{6}$

It is not by accident that black bodies have been subjugated in the United States; and, it is not uniquely an American phenomenon. It is a belief system established by white Europeans through the invention of race. The invention of racial classification is credited to French physician François Bernier's A New division of Earth by the Different Species or Races which Inhabit It (1684), wherein he classifies people based on physical features such as facial type, cranial profile, hair texture. ${ }^{7}$ By the 18th century Carolus Linnaeus further defined the "races" into seven categories. ${ }^{8}$ With the 19th century an explosion of European naturalists begin publishing works on race classifying humans by their own metrics with the common foundation of demarcating Caucasians as the superior race and Negros as the lowest. ${ }^{9}$ These belief systems were then used to establish Caucasian Europeans as the dominant race and, therefore, served as a rationalization for the subjugation and colonization of the peoples of Africa (and elsewhere).

Simultaneous with the establishment of race as a category of scientific inquiry, philosophers would also provide their own racially-based rationalization for White European superiority. In his aesthetic treatise Immanuel Kant-the German philosopher credited with helping to found modern philosophical thought- referred to the black man as insignificant and subhuman. ${ }^{10}$ His successor, German philosopher Georg Wilhelm Friedrich Hegel would state that Africa had no significance to the history of man and had no value. ${ }^{11}$ He would describe its people as amoral and soulless. Out of these belief systems the social construct of whiteness emerges. ${ }^{12}$

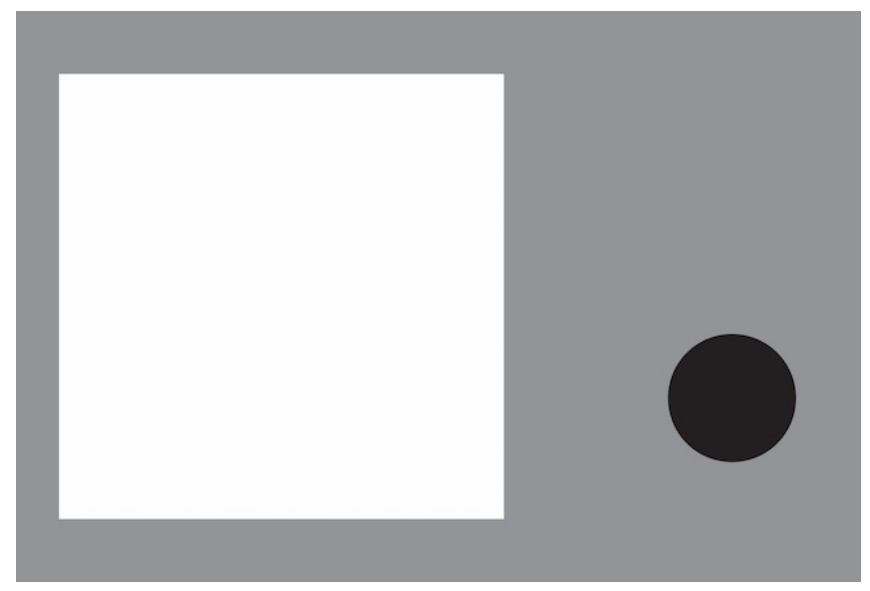

Figure 1: Diagram showing Whiteness' perceived position with Blackness. Blackness sits outside of Whiteness..

The construct of whiteness is so embedded into American ideology it is often believed to be the (neutral) truth. As a condition of neutrality, whiteness is rarely critiqued or challenged by white bodies. For example, the concept of public space in the United States is seen as a neutral one; and yet is defined by white values, beliefs, rituals and practices as the "normative" or "neutral" condition for public space. The recent discussions regarding Confederate flags and monuments in public parks is one such example. As journalist Ta-Nehisi Coates states: "The Confederate flag's defenders often claim it represents 'heritage not hate'."13 But "heritage" in this case is a mask behind which whiteness (and racism) hides. In his "Corner Stone" speech given at the start of the Civil War, Alexander Stephens made this notion of whiteness as heritage explicit:

Our new government is founded upon exactly the opposite idea [of equality of the races]; its foundations are laid, its corner-stone rests, upon the great truth that the negro is not equal to the white man; that slavery subordination to the superior race is his natural and normal condition. This, our new government, is the first, in the history of the world, based upon this great physical, philosophical, and moral truth. ${ }^{14}$

Coates notes that this "moral truth" as embodied in the Confederate flag is what animates white supremacists. It is not a leap, therefore, to demonstrate that it is the same for the Confederate monuments which adorn "public" parks and spaces. The 1500 public Confederate-related monuments in 31 states racializes the notion of public space; and, therefore, communicates different messages to different publics about the nature and occupation of the built environment. ${ }^{15}$ Ultimately, under the pretence of heritage, Confederate flags and monuments promote a notion of public space that is founded in whiteness.

For those who sit outside of whiteness, they are constantly forced to prove themselves worthy to exist in the same space 


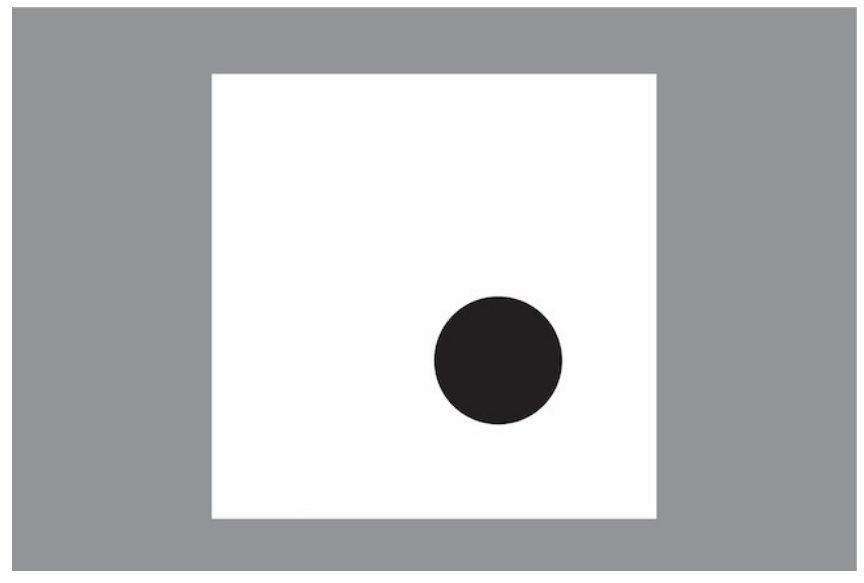

Figure 2: Diagram shows the true relationship between Whiteness and Blackness. Blackness is a construct created by Whiteness to prop itself up and justify its control over black bodies..

of whiteness. This is a game that blackness can never win, because by definition blackness can never be equal to whiteness (as noted by Stephens speech and in the aforementioned scientification of race). When black bodies try to critique or challenge whiteness, it is met with a resistance that, at best, is a reaction of ignoring the challenger and at worse physical violence (the 2017 riots in Charlottesville, Virginia in a Confederate monument adorned park are just one in many examples of this phenomenon). When black bodies exist in white space it is often seen as suspicious. This manifests itself in a variety of ways when black bodies occupy public/ white space: being followed by security in an outdoor mall; being questioned as to one's presence on a college campus; being interrogated by police for being in a park, on the street, or on a front porch or stoop. The normative/white assumption assumes that black bodies in the built environment are criminal, intellectually inferior, and/or undeserving. Whiteness becomes a structural system that ensures the continued dominance of white bodies. It is a tool to legitimize the oppression of the "otherness" of black bodies. It is such a prevailing structural system that ties to the origins of the United States, that architectural education and praxis reinforce it as a neutral condition, because it is assumed to be the (white) American condition.

Historian Dolores Hayden has commented on this condition by noting, "One of the consistent ways to limit the economic and political rights of groups has been to constrain social reproduction by limited access to space." ${ }^{16}$ Thus, different groups understand public space differently and people's experience of spaces are not often revealed or made visible in the complex politics of space that over lap with issues of identity, heritage, and experience; particularly when whiteness has rendered those spaces as neutral in the prevailing discourse. A notion of blackness asserting itself in public space is similar to proposals made by feminist philosopher Iris Marion Young who asserts that city life should not aspire to community (which excludes those not a part of the predominating homogenous group) but to "difference without exclusion."17 This aligns with Lefebvre's proposition of the right to the city as the right "to urban life, to renewed centrality, to places of encounter and exchange, to life rhythms and time uses, enabling the full and complete usage of [...] moments and spaces."18 In proposing a definition of city life in which togetherness is defined by the coming together of strangers rather than the sharing of a common culture or values, Young asserts that urbanity should emphasize a publicness that is "heterogeneous, plural, and playful, a place where people witness and appreciate diverse cultural expressions that they do not share and do not fully understand." ${ }^{19}$ Sociologist Don Mitchell concurs noting that, "in the city, different people with different projects must necessarily struggle with one another over the shape of the city, the terms of access to the public realm." ${ }^{20}$ Within the theoretical rubric outline above, the discourse of community is one of whiteness and the discourse of difference is one of blackness. Currently, place-making via architectural design in the United States is ruled by an ideology of community (aka whiteness) rather than one of difference (aka blackness). While geographer Kath Browne has asserted that the conceptual ion of queer "seeks to reconsider how we think [of] our modes of being and our conceptualizations of politics," ${ }^{21}$ this paper uses the term blackness to underline a similar conceptualization of the production of architecture and architects.

As aforementioned, starting in the 18th century, and continuing in earnest in the 19th and 20th centuries, in Europe and North America both the humanities and the sciences would affirm a social construction of whiteness whose outcome was to limit and control the movement of black bodies. ${ }^{22}$ The black body was (and is) kept in place by the creation of laws, policies, and the normative reinforcement of belief systems based on this "scholarly inquiry." 23 In the United States, this historical cultural construct still operates based on a whiteness belief that it has the right to police and control black bodies; and, a right to appropriate all that a black body produces. ${ }^{24}$

Historically the displacement and fear of black bodies is a tool used by the construct of whiteness to prop itself up as superior to all other races and to legitimize the oppression of black bodies in the United States. As much as the construct of whiteness asserts that blackness sits outside of whitenessand that the American experience is based on white European values-it is not. ${ }^{25}$ American culture has, in large part, been produced by black experiences. Black Americans have contributed significantly to music, literature, art, sciences, and food, as well as, all other aspects of American life. ${ }^{26}$ In the context of the United States blackness sits firmly in whiteness not outside of it. Much of what blackness has generated in terms of culture has been that of remixing and reinterpreting white Eurocentric values with African culture, creating a distinct voice that can only be described as American. ${ }^{27}$ 


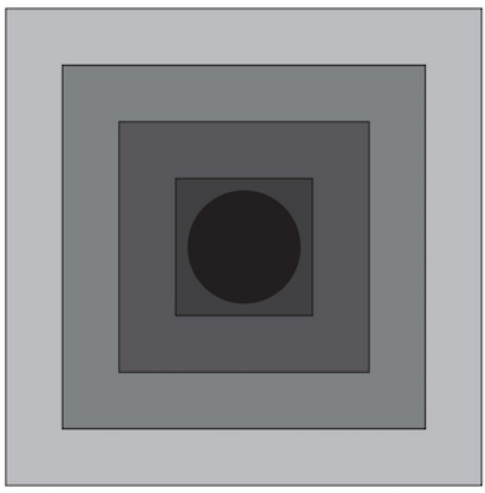

Figure 3: Diagram shows that in-order to control Blackness it must build a system of barriers to limit access to spaces..

The problem of whiteness is also an architectural problem, because the regime of architecture refuses to be critical of its continuing role of the erasure and confinement of black bodies in the United States. Architecture is all too willing to align itself with whoever is in power or who has funding (as is implicit in Ivy's statement), which has often allowed itself to be used as a tool for the continued oppression on the "other."

\section{THE RACIAL PRODUCTION OF ARCHITECTURE \& BLACKNESS IN THE CURRICULUM}

"[...] the white reader is invited to reexamine her customary ways of thinking about whiteness and, consequently, to reevaluate her attitude toward the concept of race-neutral decision making. There is a profound cognitive dimension to the material and asocial privilege that attaches to whiteness in this society, in that the white person has everyday option not to think of herself in racial terms at all. In fact, whites appear to pursue that option so habitually that it may be a defining characteristic of whiteness: to be white is not to think about it. I label the tendency for whiteness to vanish from whites' self-perception the transparency phenomenon." -Barbara J. Flagg ${ }^{28}$

"However, if I seem to repeat things you have heard before, I do not apologize, any more than I think a physician would apologize for giving inoculations. [...] One need only take a casual look at this audience to see that we have a long way to go in this field of integration of the architects." -Whitney Young ${ }^{29}$

Design is not neutral and neither is architecture (in its pedagogies, processes and products). Yet, so many in the field of architecture believe that architecture is just that, neutral and a-political. Design itself is the purposeful planning of a solution to a problem. Human problems have contexts and those contexts are political. Practitioners and educators choose to ignore the full (ethical and socio-political) implication of designs. While the profession and discipline finds it easy to rally around issues of sustainability and efficiency,

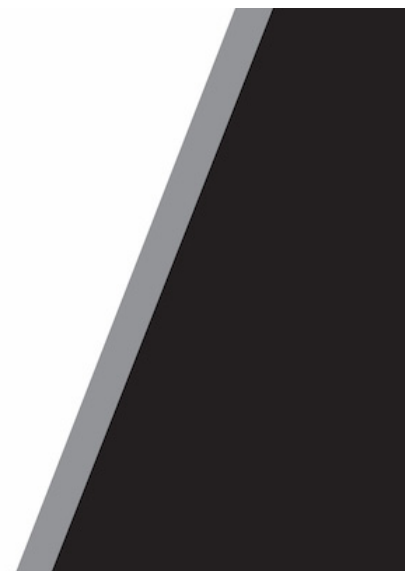

Figure 4: Diagram shows where Blackness and Whiteness intermix, mostly for the entertainment of Whiteness.

conversations about race are minimal to non-existent. The ideology of neutrality allows its practitioners to be, at the least, complicit in the role of architecture in perpetuating racism in the United States. This unwillingness to engage in conversations about race has, in part, made architecture less relevant in American society by excluding those who are seen as "other." In order to start this conversation, it must begin with architectural learning institutions. This must go deeper than filling some quota, and educators must understand this is not just about who is in architecture school and who is in practice (although those are critical issues), but the conversation needs to expand beyond demographics. ${ }^{30}$

The question is how to initiate a direct conversation about race in institutions of learning-beyond a vagueness about low income housing or public interest design-when only three percent of faculty and five percent of students in the United States are Black. This conscious reflection on the naturalization of whiteness in architecture needs to begin with a primarily white constituency; particularly amongst a professorate where an overwhelming majority of white full and associate professors provide primary leadership roles in the shaping of curricula. Thus, all faculty and students need to know how we got here and have the opportunity to selfreflect to gain an insight into their own biases. It must be acknowledged that what is required is not easy. Educators in schools of architecture are constantly struggling to meet the requirements of $\mathrm{NAAB}$, but even more difficult for instructors is talking about race. It requires the academy to be brave, because as a nation the explicit conversation of whiteness and blackness has been removed from all levels of education. It requires white educators to become self-aware of their own privilege and biases and the neutrality with which they communicate the design of public spaces and buildings in particular. These conversations can begin in multiple areas in architecture schools by including Black American architects in history and theory class and by having a dialog as to how and why -in spite of the global architecture movement and NAAB requirements around social responsibility 
and community engagement-they are consistently left out of history, theory, and studio discourse. Instructors can start by introducing the research of Mario Gooden, Darell Wayne Fields, Craig L. Wilkins, and Mabel O. Wilson. ${ }^{31}$

In order to pursue an agenda of prompting blackness in architecture, author B.D. Wortham-Galvin brought the NEA Artworks funded project, A Place To Be into 1 studio, 3 seminars, and 1 design-build. ${ }^{32}$ The project asked: Who makes place and who occupies it? Who is left out and behind in traditional design and development issues? What happens when a primarily white city (Portland, Oregon) and a primarily white discipline (architecture in the U.S.) tackle design-based inequities? How do spaces construct a particular worldview for their occupants; how has the discipline of architecture passed on that worldview; and, how the profession has embedded that worldview within the built environment? What does it mean when the perceptions and values of the praxis of architecture differ greatly from those with whom we are supposed to be designing? In other words, how to design with communities when the designers are primarily white and when the community-clients are not? ${ }^{33}$

Begun in 2015, A Place to Be asked why black experiences in Portland had been rendered invisible. Drawing upon oral history, participatory and social practice methods (as well as conventional research), A Place to Be innovated the notion of place-based research by documenting (just a fraction of) the varied historic and contemporary black cultural experiences, productions and impacts on the city. ${ }^{34}$ While grounded in primary data collection (archival, demographic, statistical, interviews, and community outreach) and supported by secondary source reading, the outputs were not in the form of traditional papers and reports, but rather in 2D-visualizations, short films, social media, and social art practice as a way to make place-based research visible and relevant to the place issues faced by black residents. ${ }^{35}$

The initial investigations developed into research-based design documenting potential sites, programs, and visions for a defined A Place to Be as a way of prompting conversations with and within the black community of needs, wants, and desires to ameliorate their loss of place. ${ }^{36}$ This researchbased design was done through interviews and workshops with a variety of black community organizations, leaders, and artists. ${ }^{37}$ In addition to design envisioning, short films, social media, and 2D visualization projects, performative research was initiated with the Pop Up Porch, a temporary structure meant to catalyze this research-based discussion and make it public. The methodological philosophy promoted-“We will provide the porch. You will talk. We will listen. A Conversation Experiment to discuss creating a space in Portland where Black Art and Culture is created, taught, discussed, celebrated and witnessed"38 - was critical to innovating research within a culture of oral traditions. ${ }^{39}$
The A Place to Be Project (in its pedagogy, processes, and outcomes) affirms that the responsibility of ensuring challenges to prevailing architectural pedagogies cannot and should not rest solely on black bodies. That is a trap of whiteness; expecting the "other" to educate and prove itself. Ownership of the dismantling of racism must come from white bodies. At the moment, one quickly realizes just how white of a space most architecture schools are. Blackness is absent in its history, theory, studios, faculty, and student body. This ensures whiteness' ownership of architectural design, allowing white bodies to decide what has value and who gets credit ensuring whiteness' continued oppression of the "other." While Young's AIA speech is usually quoted in a singular sentence regarding the responsibility of the architect, he also notes that this discourse of blackness is critical for all of those left out and left behind of design and development discussions:

[...] I make no apology for singling out the Negro, although I am fully aware that there are poor white people in Appalachia, poor Mexican-Americans, poor Puerto-Ricans and Indians. The Negro is a sort of symbol, the only involuntary immigrant in large numbers, sort of a symbol of it. [...]The Negro has been largely the victim, not of active hate or active concern, but active indifference and callousness. [...]Our sin, then, is the sin of omission and not of commission, and into that vacuum have rushed the prophets of doom, the violent people, the vicious people who hate, and they have come all too often around the world to be the voice of America. ${ }^{40}$

This will continue to be the case until white bodies are willing to have those conversations and challenge whiteness themselves. Trump and his administration is counting on the complacency of white bodies to ensure the continuation of the ideology of whiteness. By engaging in talking about race's spatial, aesthetic, and social implication we directly dismantle the power of Trump and those who advocate the oppression of the "other." This will not happen overnight, but it will never happen if architectural educators and practitioners don't start leaning into it. Leaning into it means that it is a conversation that doesn't happen in one class room, but rather it happens in multiple classes and at multiple levels.

\section{ENDNOTES}

1 Whitney Young. "Unedited transcript of the speech made to the American Institute of Architects in 1968." 20 on 20/20 Vision. Perspectives on Diversity and Design. Linda Kiisk, ed. (Boston: Boston Society of Architects, 2003): 16, 18.

2 Statement released by Robert Ivey, AIA executive vice president and chief executive office on behalf of the national AIA membership. This statement is no longer available on the AIA website (taken down presumably following the backlash). Several architecture news outlets quote it, including: "AIA pledges to work with Donald Trump, membership recoils," The Architects Newspaper, Nov 11, 2016. Accessed September 8, 2017 https://archpaper.com/2016/11/ aia-pledges-work-donald-trump-membership-recoils/

3 Whitney Young's quote is well known by those who work in community and/ or public interest design, but less so to the architectural discipline and professional in general.

4 Michael Sorkin, "Architecture Against Trump," open letter published in response to Robert Ivey's AIA statement, 12 Nov 2016. Accessed 11 September 2017 https://www.dropbox.com/s/ddt6l23bl7alxq1/Architecture\%20 Against\%20Trump\%20by\%20Michael\%20Sorkin.pdf 
5 NCARB numbers are quoted from The Architects Newspaper, op cit. The Directory of African American Architects accessed on 8 September 2017 listed 1733 male licensed architects and 403 female licensed architects, for a total of 2136 registered African American architects listed in their data base. < http:// blackarch.uc.edu/>

6 W. Young, op cit, p. 14

7 Sue Peabody and Tyler Stovall. The Color of Liberty: Histories of Race in France. (Durham: Duke University Press, 2003).

8 Carolus Linnaeus. Systema Naturae, 1735, Trans MSJ Engel-Ledeboer and H Engel. (Amsterdam: Brill - Hes \& de Graaf, 1964)

9 Johann Friedrich Blumenbach classified black bodies as the Ethiopian race. Louis Agassiz referred them as the African zoological race, Thomas Huxley used Negro race. Joseph Arthur Comte de Gobineau referred to them simply as the Black race. Pickering, Charles. The Races of Man: And Their Geographical Distribution. Reprint. Ann Arbor: University of Michigan Library. 2009

10 Kant, Immanuel, Patrick R. Frierson, and Paul Guyer. Kant: observations on the feeling of the beautiful and sublime and other writings. (Cambridge: Cambridge University Press, 2011).

11 G.W.F. Hegel, Lectures on the Philosophy of World History, trans. H.B. Nisbet. (Cambridge: Cambridge University Press, 1971).

12 Tim Wise. Colorblind: The Rise of Post-Racial Politics and the Retreat from Racial Equity. (San Francisco: City Lights Books, 2010).

13 Ta-Nehisi Coates, "Take Down the Confederate Flag-Now," The Atlantic, June 18, 2015, accessed 22 September 2017 < https://www.theatlantic.com/politics/ archive/2015/06/take-down-the-confederate-flag-now/396290/>.

14 "Corner Stone" Speech, Alexander H. Stephens, Savannah, Georgia, March 21, 1861, accessed 22 September 2017 < http://teachingamericanhistory.org/ library/document/cornerstone-speech/>. The Teaching American History website notes that this speech was published in the following book: Henry Cleveland, Alexander H. Stephens, In Public and Private: With Letters and Speeches, Before, During, and Since the War (Philadelphia, 1886), pp. 717-729.

15 These numbers rely upon federal, state, and local databases as reported from David Graham, "The Stubborn Persistence of Confederate Monuments," CityLab, April 27, 2016, accessed on 22 September 2017 < http://www.citylab. com/amp/article/480228/>.

16 Hayden, D. (2014). Urban Landscape History: The Sense of Place and the Politics of Space. In J.J. Giesking \& W. Mangold (Eds.), The People, Place, and Space Reader. New York: Routledge. (Originally published 1995), 83.

17 Iris Marion Young explicates the concept of difference. Young, I. M. (1990). Justice and the Politics of Difference. Princeton, NJ: Princeton University Press, 247.

18 Lefebvre, H. (1996). The Right to the City. In E. Kofman \& E. Lebas (Eds.), Writing on Cities, Oxford: Blackwell. (Original Work published 1968), 179.

19 I. M. Young, op cit, 251.

20 Mitchell, D. (2014). To Go Again to Hyde Park: Public Space, Rights, and Social Justice. In J.J. Giesking \& W. Mangold (Eds.), The People, Place, and Space Reader. New York: Routledge. (Originally published 2000), 193.

21 Browne, K. (2006). Challenging Queer Geographies. Antipode xx, 889. Brown references Halberstam, J. (2005). In a Queer Time and Place: Transgender Bodies, Subcultural Lives. New York: New York University Press at the end of this sentence.

22 Seminal discussions of the socio-politics of race in the United States include: 1. James Baldwin, Collected Essay (1998); 2. Cornel West, Race Matters (1993); 3. Tim Wise, Colorblind: The Rise of Post-Racial Politics and the Retreat from Racial Equity (2010). Important sources for the history of race in the United States include: 1. Ibram X. Kendi, Stamped From The Beginning: The Definitive History of Racist Ideas in America (2016); Jacqueline Battalora, Birth of a White Nation: The Invention of White People and Its Relevance Today (2013). For the implications of racial constructions of aesthetics, refer to: 1 . Darell Wayne Fields, Architecture in Black (2000); 2. Mario Gooden, Dark Space (2016); 3. Darby English, How to See a Work of Art in Total Darkness (2010).

23 This control began with slavery in the United States as the legal institution of human chattel that existed after the colonies gained independence and up to the end of the American Civil War. The rapid expansion of the cotton industry in the Deep South after the invention of the cotton gin led the Southern states to depend on slavery as integral to their economy. At the time, the United States Constitution was ratified (1789), a relatively small number of free people of color were among its voting citizens. During and immediately following the Revolutionary War, abolitionist laws and sentiment began in the Northern states; in addition, as most of these states had a higher proportion of free labor, they abolished slavery by the end of the 18th century, some with gradual systems that did not free the last slave until the 1800 s. Southern states attempted to extend slavery as an institution into the new Western territories, believing that slavery had to expand or it would die. In addition to slavery, control of black bodies was reinforced by the Black Code laws (1800-1865) that legally restricted the civil rights and civil liberties of African Americans; and, as a consequence negated any potential for a free and open relationship to public space and the public sphere. While Congress did abolish slavery via the passing of the Thirteen Amendment to the United States Constitution (1864), the Black Codes and the subsequent Jim Crow laws continued to restrict black bodies from freedom and agency. (See Ibram X. Kendi. Stamped from the Beginning The Definitive History of Racist Ideas in America. (New York: National Books, 2016).) Jim Crow laws were state and local laws mandating de jure racial segregation in all public facilities in the former Confederate States of America, starting in 1890 with a "separate but equal" status for African Americans. This body of law institutionalized a number of economic, educational, and social disadvantages that had tangible consequences in how the built environment was made and occupied. De jure segregation mainly applied to the Southern United States, while Northern segregation was generally de facto - patterns of housing segregation enforced by private covenants, bank lending practices, and job discrimination. Jim Crow laws mandated the segregation of public schools, public places, public transportation, and the segregation of restrooms, restaurants, and drinking fountains for whites and blacks until overturned in 1964-5.

24 Appropriation of black bodies productions has been most been focused on music and hip-hop culture. We see it appropriated by white clothing designer to white musicians.

25 Wise, op cit, (2010)

26 Black culture begins as a subculture. This concept has been articulated fully by Dick Hebdige. Dick Hebdige, Subculture: The Meaning of Style (London: Methuen, 1979)

27 An example of this appropriation is the use of the color haint blue in the painting of porches in the United States. Today many people paint the ceilings and/ or trim of their porches various shades of blue-green that paint manufactures have renamed from the original: haint blue (Miller Paints based on the West Coast calls this shade of blue "verandah blue." The first painted strokes of haint blue in the United States adorned not the homes of the rich, but the simple shacks of African slaves. The original haint blue creators worked on plantations. Many of their ancestors came from Angola, and are well known for preserving their African heritage. They kept alive the traditions, stories, and beliefs of their ancestors, including a fear of haints. Haints, or haunts, are spirits trapped between the world of the living and the world of the dead, who are unable to cross over water. The slaves had an elegant solution. They created the haint blue paint to look like water so the spirits would become confused and tricked into thinking they could not enter. The slaves used this color to paint their porches and other openings in their homes. The tradition of painting porch ceilings haint blue continues today and demonstrates how African heritage is a part of American culture even though it has been rendered invisible by the culture of whiteness.

28 Barbara J. Flagg. "Was Blind, but Now I See: White Race Consciousness and the Requirement of Discriminatory Intent." Michigan Law Review. Vol 91, No. 5 (March 1993). P 969

29 W. Young, op cit, p. 9.

30 The 2016 Annual NAAB report notes that only $3 \%$ of faculty are Black/AfricanAmerican (a total of 161 persons). While enrollment by white students has been steadily declining since 2009 , NAAB notes that enrollment of Black/ African-American students has remained flat over the past five years at $5 \%$ of enrollment each year (the fastest growing category of non-whites is nonresident alien). 2016 NAAB Report, Parts 1 and 2 accessed 14 September 2016 <http://www.naab.org/wp-content/uploads/NAAB_2016AnnualReport_Part1. pdf > and < http://www.naab.org/wp-content/uploads/2016-NAAB-Report-onAccreditation-in-Architecture-part-II.pdf >

31 Darell Wayne Fields. Architecture in Black. London: Athlone Press, 2000. Mario Gooden. Dark Space: Architecture, Representation, Black Identity. New York: Columbia University, 2016. Mabel O. Wilson. Negro Building: Black Americans in the World of Fairs and Museums. Berkeley: University of California Press, 2012

32 Author B.D. Wortham-Galvin participating in multiple classes and activities of A Place To $B e$ as a graduate student.

33 Further discussion of the issue of agency and how it enters into the pedagogy of academy can be found in work of Paolo Freire and xxx. Paolo Freire, Pedagogy of the Oppressed: trans. Myra Bergman Ramos (New York: Continuum Books, 2000); and, B.D. Wortham-Galvin, "Agency and Actions in the Making of Contemporary Place," Dialectic IV (September 2016), 28-42. The A Place to Be project was presented by authors xxx and xxx under the title "A Place To Be: Rendering Black Bodies Visible," at the AAE Conference Architecture Connects, Oxford Brookes University, Oxford, UK, September 2017.

34 It should be stressed that these experiences and productions are plural and that no one historical or contemporary black person represents the urbanism of the whole. That being said, students were strongly encouraged to be specific in focus for each film in order to avoid generalizations. Urban issues that formed the basis of the place research included: poverty, affordable housing, access to food, economic opportunities, environmental justice, access to transportation, neighborhood formation, access to institutions, education, complete streets, displacement, right to return, urban agriculture, etc.

3535 . An example of an engaged visualized research component included using the social media platform Instagram - and a corollary hashtags \#blacksoulpdx and \#blackpdx - to create an interactive mapping resource. Students started the research by using Instagram as a tool to geo-tag and hash-tag locations in real time. But the tool is democratic and participatory in that anyone and everyone can participate. Thus both residents and visitors to Portland became a part of the map production.

36 B.D. Wortham-Galvin has been influenced by Peter McLaren in establishing 
a critical pedagogy and therefore process. Peter McLaren, Critical Pedagogy and Predatory Culture: Oppositional Politics in a Postmodern Age (London: Routledge, 1995), 231. The design process articulated by B.D. Wortham-Galvin and pursued through the grant included the following goals, strategies and objectives: Finding plural ways to engage people in the discussion of their needs and desires in order to achieve co-production. Using design-thinking to find opportunities within a disinvested community and recognizing and supporting what is already successful. Rethinking static notions of cultural and community centers by supporting new hybrids that respond specifically to the constituents. Using architectural design as a way to construct a conversation between multiple partners - not as an offering of a finite solution. Visualizing research and conditions so they become more apparent to stakeholders at all levels. Having both students and community members embrace culture as a process that is lived; not a product to be displayed. Using a mix of strategies (instead of one) to stimulate community dialogue in order to broaden the base of whom might be involved and continue to cycle through response to see which ones continue to resonate over time and with many people (versus those that are singular and/or temporary concerns). Having students frame their work through a series of questions rather than declarations in order to destabilize the authority of the architect and promote the agency of the "user". To challenge the notion of who is an expert and/or what qualifies as expertise. To challenge the notion of culture as static, inert, and/or singular. To include the agency of everyday people in the design of the built environment.

37 The A Place to Be website is documenting (just a fraction of) the varied historic and contemporary Black cultural experiences, productions and impacts on the city of Portland. On this website you will find a few examples in the form of films and visualizations that are meant to prompt a larger discussion of the even more diverse cultural productions and experiences by Black Portlanders occurring in the past, present, and future. Making visible both the historical and contemporary experiences and productions of black residents in Portland, research outputs include infographic visualization posters and short films revealing institutionalized displacement, gentrification, marginalization and dispersal of black residents.

38 These words were written by black journalist and artist Renee Mitchell early in the process.

39 The Porch is meant to catalyze this discussion and to witness how Black Arts and Culture matters to Portland. In doing so, the Porch as a temporary installation aimed to call attention to the need for a permanent, public center to celebrate African American and Black arts in Portland. The intent was to start a discussion on the Porch that will continue and hopefully result in a permanent facility. Why provide a porch? Historically the porch has figured prominently in African American heritage for centuries in the United States as a place for family, friends, gathering, storytelling, cooking, sewing, singing, music, and conversations both important and mundane. Expressing plans and dreams would all happen on the porch as the only historically accessible public space for African-Americans. The porch is painted haint blue because the first painted strokes of the color were in the simple shacks of African slaves. Haints are spirits trapped between the world of the living and the dead, who are unable to cross over water. The slaves had an elegant solution. They created the haint blue paint to look like water so the spirits would become confused and tricked into thinking they could not enter. The slaves used this color to paint their porches and other openings in their homes. The now ubiquitous tradition of painting porch ceilings haint blue continues today and demonstrates how African heritage is a part of American culture. For a month, the Porch occupied a park on the corner of SW 12th Avenue and Market Street, providing a public place for all manner of creative works and discussions celebrating and originating in Portland's Black community. The goal was to create a focused space for Portland's Black Arts to be viewed, experienced, cherished, and discussed in the public sphere, in order to highlight the need for a permanent Black Arts and Cultural Center.

40 Young, op cit. p. 12.

\section{IMAGES}

All images created by Jackie Joseph Paul McFarland. 